\title{
Manequim vídeo cirúrgico: recurso para o ensino de médicos residentes
}

\author{
Alex Monteiro Leal da Paixão \\ Mestre em Ensino em Ciências da Saúde e do Meio Ambiente pelo UniFOA \\ Carlos Alberto Sanches Pereira \\ Doutor em Biotecnologia Industrial (USP), Docente do Programa de \\ Pós graduação em Ensino de Ciências da Saúde e do Meio Ambiente do UniFOA \\ $\triangle$ sanches68@gmail.com \\ Ana Paula Cunha Pereira \\ Doutora em Educação Física pela UNICAMP (2012), Docente do Programa de \\ Pós graduação em Ensino de Ciências da Saúde e do Meio Ambiente do UniFOA \\ $\triangle$ acunhapereiraa@gmail.comr \\ Lucas Peres Guimarães \\ Mestre em Ensino de Ciências pelo IFRJ \\ Discente do Doutorado em Ensino de Ciências do IFRJ \\ $\triangle \underline{\text { lucaspegui@hotmail.comr }}$
}

\begin{abstract}
Resumo:
O principal objetivo desse trabalho é relatar o desenvolvimento de um material didático para o ensino de vídeo cirurgia para médicos residentes. Foi desenvolvido um manequim cirúrgico de apoio ao ensino de técnicas iniciais como recurso didático, em um serviço de residência de cirurgia geral de um hospital municipal na cidade de Volta Redonda/RJ. Presenteando os passos da sua construção, e propondo um exercício como forma de treinamento, através da simulação no manequim dos atos básicos do vídeo cirurgia e por fim aplicar o exercício proposto na utilização do Manequim Cirúrgico para validação com os residentes de cirurgia geral. A Metodologia utilizada foi uma pesquisa qualitativa aprovada seguido da construção do manequim cirúrgico; construção do protótipo; demonstração da realização do exercício no manequim em aulas práticas; e, aplicação de questionário após realização do exercício proposto. Como resultado pôde-se concluir que o exercício é passível de ser realizado pelos residentes, demonstrando que o manequim pode ser usado como recurso didático e que os residentes se mostraram mais seguros com a prática cirúrgica no manequim contribuindo para a formação cirúrgica.
\end{abstract}

Palavras-chave: Vídeo cirurgia, Médicos residentes, Formação cirúrgica.

\section{Manikin surgical video: appeal to the teaching of residents physicians}

\begin{abstract}
:
O main objective of this study is to report the development of a didactic material for the teaching of surgery video for resident physicians. A surgical dummy was developed to support the teaching of initial techniques as didactic resource in a service of residence of General Surgery of a municipal hospital in the city of Volta Redonda / RJ. Giving the steps of its construction, and proposing an exercise as a way of training, through the simulation on the manikin of basic acts of video surgery and finally apply the proposed exercise in the use of surgical dummy for validation with the residents of general surgery. The methodology used was a qualitative research approved followed by the construction of a surgical dummy; construction of the prototype; demonstration of the implementation of the exercise on the manikin in practical classes; and, application of questionnaire
\end{abstract}


after completion of the proposed exercise. As a result might conclude that the exercise is likely to be achieved by the residents, demonstrating that the manikin can be used as a teaching resource and that the residents were more secure with the surgical practice in the manikin contributing to surgical training.

Keywords: Surgery video, Resident physicians, Surgical training.

\title{
Maniquí video quirúrgico: Llamamiento a la docencia de médicos residentes
}

\begin{abstract}
Resumen:
El objetivo principal de este trabajo es informar sobre el desarrollo de un material didáctico para enseñar la cirugía de video a los médicos residentes. Se desarrolló un maniquí quirúrgico para apoyar la enseñanza de técnicas iniciales como recurso didáctico en un servicio de residencia de cirugía general de un hospital municipal en la ciudad de Volta Redonda / RJ. Presentando los pasos de su construcción, y proponiendo un ejercicio como forma de entrenamiento, a través de la simulación ficticia de los actos básicos de la cirugía de video y finalmente aplique el ejercicio propuesto en el uso del muñeco quirúrgico para la validación con los residentes de cirugía general. La metodología utilizada fue una investigación cualitativa aprobada seguida de la construcción del maniquí quirúrgico; construcción prototipo; demostración del ejercicio sobre el maniquí en clases prácticas; y la aplicación de un cuestionario después del ejercicio propuesto. Como resultado, se podría concluir que el ejercicio puede ser realizado por los residentes, lo que demuestra que el maniquí se puede utilizar como un recurso didáctico y que los residentes estaban más seguros con la práctica quirúrgica en el maniquí contribuyendo al entrenamiento quirúrgico.
\end{abstract}

Palabras clave: Cirurgía de vídeo, Médicos residentes, Entrenamiento quirúrgico.

\section{INTRODUÇÃO}

Animais para fins didáticos eram muito utilizados no passado, porém, a legislação tem feito sérias restrições quanto ao uso dos mesmos, uma vez que a ação de sociedades protetoras dos animais tem se concretizado com intenso profissionalismo buscando sua proteção. Sendo assim, outros métodos de ensino da técnica operatória têm sido utilizados, preservando a qualidade do ensino-aprendizado deste importante conteúdo do currículo médico (ZANETTI, 2009).

Com o advento da Lei 9.605, que entrou em vigor no dia 30 de março de 1998, cujo grande mérito foi o de transformar em crime o que antes era apenas uma contravenção, a crueldade para com animais sob a prática da dissecção, passou a ser considerada delituosa caso não adotados os métodos alternativos existentes, tanto no Brasil como em vários outros países, conforme dispõe o artigo 32, § 1ํ: "Praticar ato de abuso, maus-tratos, ferir ou mutilar animais silvestres, domésticos ou domesticados, nativos ou exóticos: Pena de detenção, de três meses a um ano, e multa" (BRASIL, 1998). 
Em relação a esfera pedagógica, Valente (2012) descreve que o movimento Ciência, Tecnologia e Sociedade (CTS), têm como meta estimular nos estudantes de ciências médicas o interesse das aplicações tecnológicas no cotidiano. Para que isso aconteça torna-se necessário que a formação do professor seja contida de elementos que possam levá-lo à construção do conhecimento sobre técnicas e tecnologias tornando-se possível a integração na prática pedagógica.

Para que residentes do Curso de Medicina adquiram habilidades adequadas por meio da disciplina de Cirurgia, torna-se relevante que o ensino seja inovado por métodos alternativos, transmitindo informações necessárias para sua formação. Dessa forma, não utilizando animais em aula práticas dessa disciplina torna-se necessário estimulá-lo com outras alternativas para participação de atividades práticas, desenvolvendo habilidades que deverão ser exaustivamente trabalhadas durante sua especialização, preponderantemente, aquelas que se referem aos tempos básicos do ato operatório, ou seja, diérese, hemostasia, e síntese (MONDARDO e PEDON, 2011).

Atualmente vivemos dias de cirurgias minimamente invasivas, possibilitadas pela videolaparoscopia e o ensino dessa técnica operatória ao médico residente de cirurgia geral, ocorre durante uma cirurgia propriamente dita, visto que o custo do equipamento de videolaparoscopia atinge cifras que inviabilizam seu uso como simulador durante o período da graduação, o que limita este residente no desenvolvimento de suas habilidades, pois um erro poderá culminar em agravo à saúde do paciente.

Por isto, o presente trabalho tem como proposta apresentar a criação de uma ferramenta didática, representada por um Manequim Vídeo Cirúrgico de baixo custo, que poderá ser utilizado para o ensino das técnicas e movimentos básicos do vídeo cirurgia, articulado às metodologias de ensino-aprendizagem para os residentes de cirurgia geral de um Hospital municipal, em Volta Redonda/RJ.

O foco desta pesquisa localiza-se nas tendências pedagógicas da formação médica, pois existem várias habilidades e competências que devem ser desenvolvidas com intuito de oferecer um conteúdo básico à formação do médico cirurgião geral. o padrão tradicional começou a diferenciar-se com o desenvolvimento da pesquisa biomédica e o desenvolvimento da tecnologia, melhorando a formação do médico. No século XX a medicina recebeu críticas favorecendo sua ampliação (FLEXNER, 2010; SANTA-ROSA e STRUCHINER, 2011). 
Acredita-se que em meio de recursos alternativos para o ensino, como é o caso do Manequim Vídeo Cirúrgico citado por Rodrigues (2012), ser uma forma de desenvolver competências e habilidades psicomotoras e tornar possível que residentes de cirurgia consigam realizar exercícios de habilidade e coordenação motora através da simulação de procedimentos, utilizando-se dessas ferramentas didáticas para aumentar sua autoconfiança. Por meio de novas técnicas de ensino e treinamento de tempos operatórios básicos, o residente passa a ter mais oportunidades de construir sua aprendizagem, adquirindo conhecimentos e habilidades, tornando-se mais capaz e seguro para executar suas atividades.

O tema se torna relevante diante do crescimento do controle da qualidade do trabalho médico no Brasil, Neto et al. (2011) estudaram que existe um grande contingente de processos de erros médicos no país envolvendo ginecologistas e cirurgiões em geral, não levando em consideração a qualificação do profissional e, nem mesmo, os limites de suas atividades médicas. Sendo assim, observa-se a necessidade de uma formação técnica mais abrangente e eficaz, pois os custos financeiros da formação deste profissional estão cada vez maiores, principalmente, em atividades de alta tecnologia, como por exemplo, a vídeo cirurgia.

Desse modo, considerando a evolução das técnicas cirúrgicas, e em virtude da necessidade do aprofundamento na realização de procedimentos, este trabalho tem por objetivo geral a criação e a apresentação do Manequim Vídeo Cirúrgico como material didático, que poderá contribuir para que o médico residente de cirurgia geral não só venha a aprender, mas também, treinar e ser avaliado nas habilidades de videolaparoscopia, passando o processo de ensino-aprendizagem a ser entendido como uma possibilidade de despertar a curiosidade e o espírito investigador, ampliando assim os conhecimentos deste residente, pois ao se utilizar o manequim para o treinamento de procedimentos, espera-se que os residentes de cirurgia geral em um hospital municipal, em Volta Redonda/RJ, desenvolva suas habilidades psicomotoras, tornando-os mais confiantes e seguros na assistência ao paciente.

\section{METODOLOGIA}

A pesquisa desenvolvida foi participante Para Brandão e Borges (2007) a pesquisa participante: 
Deve-se partir da realidade concreta da vida cotidiana dos próprios participantes individuais e coletivos do processo, em suas diferentes dimensões e interações - a vida real, as experiências reais, as interpretações dadas a estas vidas e experiências tais como são vividas e pensadas pelas pessoas com quem inter-atuamos.(p.5)

Foi aplicada a 03 residentes de cirurgia geral do Hospital São João Batista em Volta Redonda/RJ, por estarem no segundo ano de Medicina e estar exercendo a prática cirúrgica, entre os dias 20 e 24 de novembro de 2017. O trabalho contou com aprovação do Comitê de Ética e Pesquisa em Seres Humanos, do Hospital São João Batista, órgão ao qual os residentes estão vinculados sob parecer CAE 73369317.9.0000.5237 para ser realizado no Laboratório de Habilidades № 16 da Escola de Ciências Médicas de Volta Redonda (UniFOA/FOA), CNPJ 32.504.995/0001-14.

O estudo foi desenvolvido em quatro fases:

(1) Construir o manequim;

(2) Metodologia de aplicação do manequim; e,

(3) Aplicar questionário.

Na primeira fase construiu-se o Manequim Vídeo Cirúrgico, utilizando matéria prima de fácil obtenção e baixo custo; na segunda fase ocorreu a construção do protótipo para auxiliar na aprendizagem; na terceira fase aplicou-se atividades práticas com tarefas que foram realizadas no ambiente vídeo laparoscópico do manequim; e, na quarta fase os residentes de cirurgia do segundo ano por já se encontrarem em atividades de prática cirúrgica, responderam a um questionário semiestruturado com 7 perguntas fechadas e 1 aberta, aplicado após a realização do exercício proposto.

\section{Construção do manequim}

Para a construção deste material didático foi utilizado um busto de manequim feminino de plástico cortado em duas metades (anterior e posterior), dando assim a ela, a forma de um tronco de uma paciente, para que se possa simular algum procedimento cirúrgico no abdome. Devido ao pequeno espaço interno existente entre as metades anterior e posterior $(18 \mathrm{~cm})$, optou-se por desprezar a metade posterior e substituí-la por um estojo 
construído de madeira, aumentando o espaço interno e possibilitando assim a realização das tarefas.

Este estojo foi feito com a silhueta igual à da metade anterior do manequim de modo que ocorresse um encaixe entre a metade do manequim e o estojo. As duas partes foram fixadas entre si com duas dobradiças, o que permite o acesso dentro da manequim, ficando o estojo ao final com um espaço interno de $30 \mathrm{~cm}$ de altura, tamanho este mais aproximado ao espaço encontrado dentro abdome quando insuflado durante a cirurgia vídeo laparoscópica. O Manequim passou a ser composto pela tampa que constituiu metade anterior e pelo estojo, que passou a ser o corpo (Figura 1).

Figura 1. Metade Anterior do Manequim

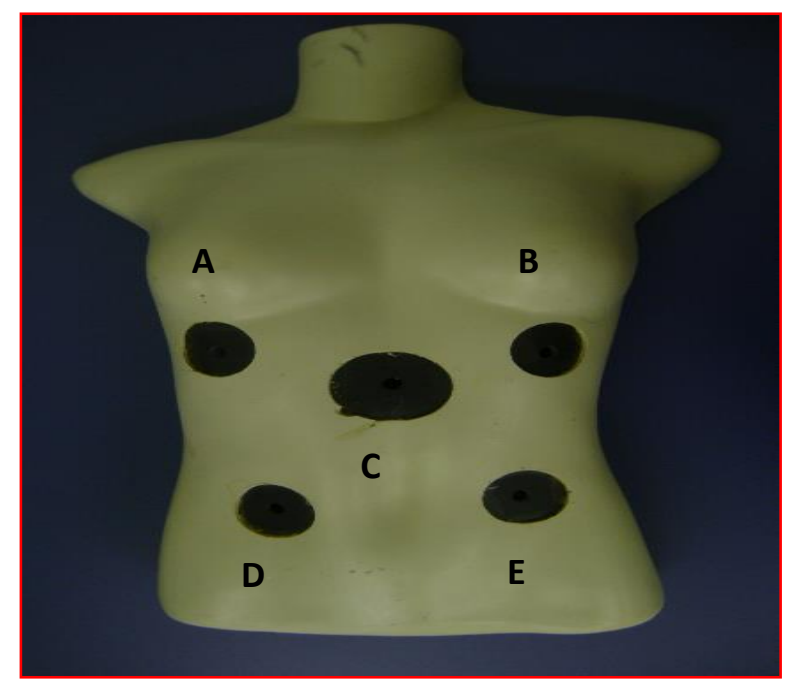

Legenda: A: orifício para introdução de instrumental B: orifício para introdução de instrumental C: orifício para introdução da câmera D: orifício para introdução de instrumental E: orifício para introdução de instrumental.

Fonte: Elaboração da pesquisa.

O estojo de madeira foi impermeabilizado com fibra de vidro para possibilitar a execução de tarefas com material úmido sem comprometer sua estrutura de madeira e finalmente pintado de branco com tinta acrílica para refletir melhor a luz interna aumentando a luminosidade (Figura 2). 
Figura 2. Parte Interna do Estojo do Manequim com espaço interno de $30 \mathrm{~cm}$ de altura

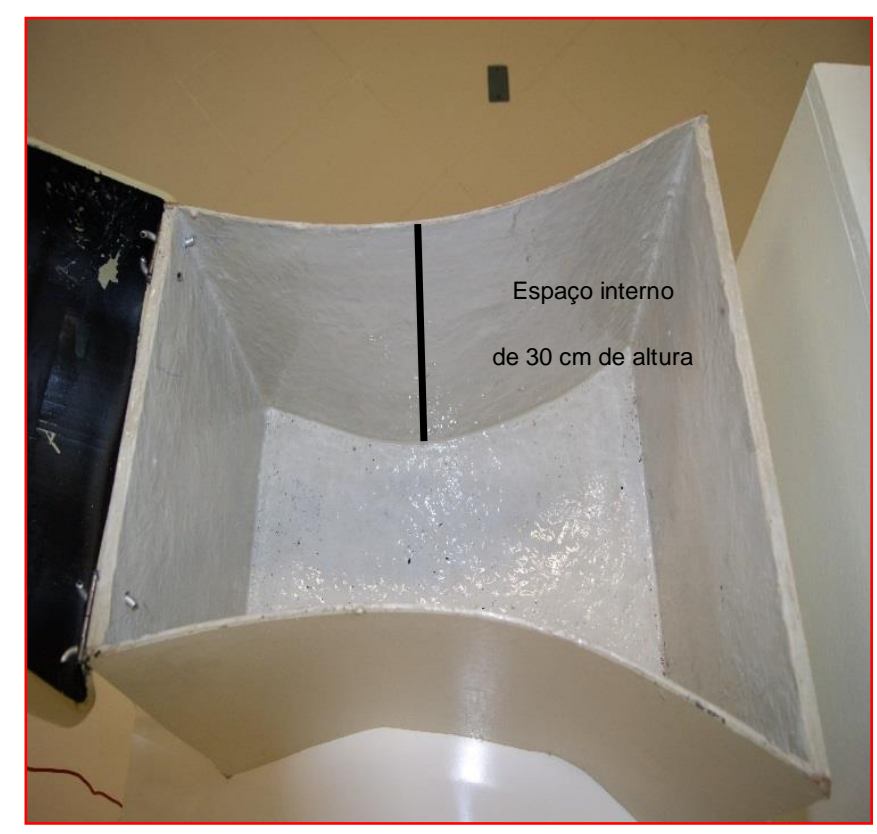

Fonte: Elaboração da pesquisa.

Na tampa foram realizados cinco furos dispostos em "X", com 4,5 cm de diâmetro. Nestes furos foram coladas internamente borrachas com um furo central de $11 \mathrm{~mm}$, de modo a permitir a colocação de portais de vídeo-laparoscopia (Trocaters), para a introdução dos instrumentais necessários à realização das tarefas e a face interna da tampa foi pintada com tinta preta, para impedir a perda da luminosidade.

O orifício central foi padronizado como o portal para a colocação da câmera de vídeo - vide descrição abaixo - por possibilitar a realização de atividades tanto no andar superior como no andar inferior do manequim. Em todos os orifícios foram utilizados trocarte de 11 mm descartáveis que foram cortados para facilitar a mobilização das pinças (Figura 3). 
Figura 3. Trocateres normal e cortado

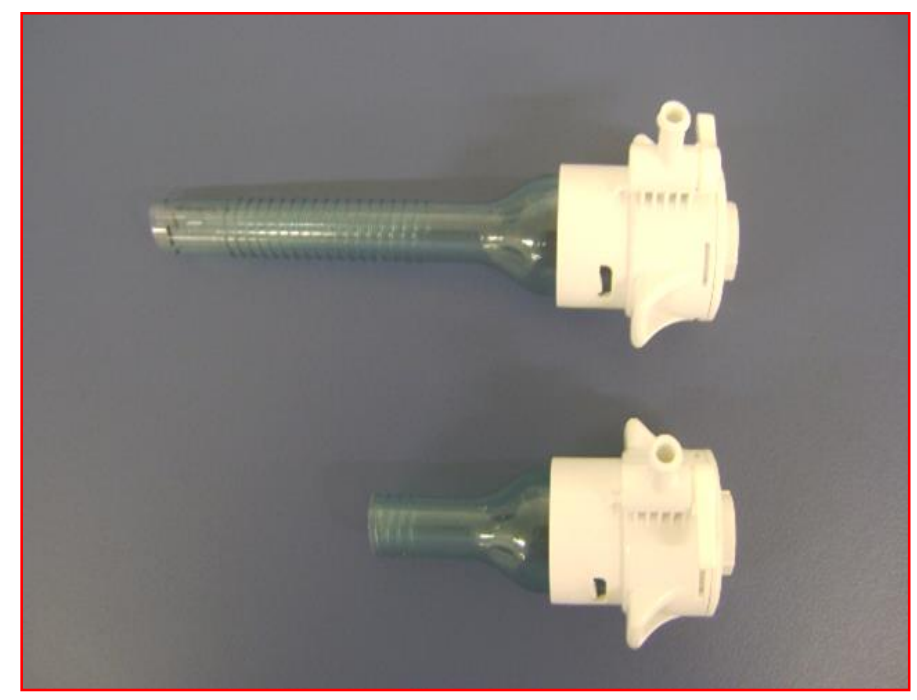

Fonte: Elaboração da pesquisa.

Para a iluminação interna optamos por uma lâmpada fluorescente de 9 Watts instalada num soquete que foi fixado na tampa e teve sua chave liga/desliga exteriorizada. Para a montagem da câmera manteve-se a premissa de fazer o Manequim com os instrumentais de menor custo possível e por isso utilizou-se uma pinça de cirurgia videolaparoscópica clipadora descartável onde somente a cânula com por possuir diâmetros diferentes, foi aproveitada após o desmonte.

A extremidade com diâmetro maior foi utilizada para a fixação de uma mini câmera modelo Sony, sensor CCD 1/3, alimentação de $12 \mathrm{Vdc}$, corrente $120 \mathrm{~mA}$, consumo de 1,44 W, iluminação Mínima de 0,5 Lux, padrão NTSC 510x492, AGC: Automático, com resolução de 470 Linhas, sinal / Ruído: High, Gamma: 0,45, temperatura de Operação entre $-10^{\circ} \mathrm{C}$ a $50^{\circ} \mathrm{C}$, lente: 3,6mm, sem áudio e dimensões H x L x P (mm): 36 x 36 x 32 mm.

Foi fabricada por um torneiro mecânico uma peça que foi acoplada na extremidade de maior diâmetro da cânula. Esta peça possui dois orifícios rosqueados para a fixação da tampa posterior da câmera utilizando parafusos conforme figura 4. 
Figura 4 - Peça utilizada para fixação da câmera.

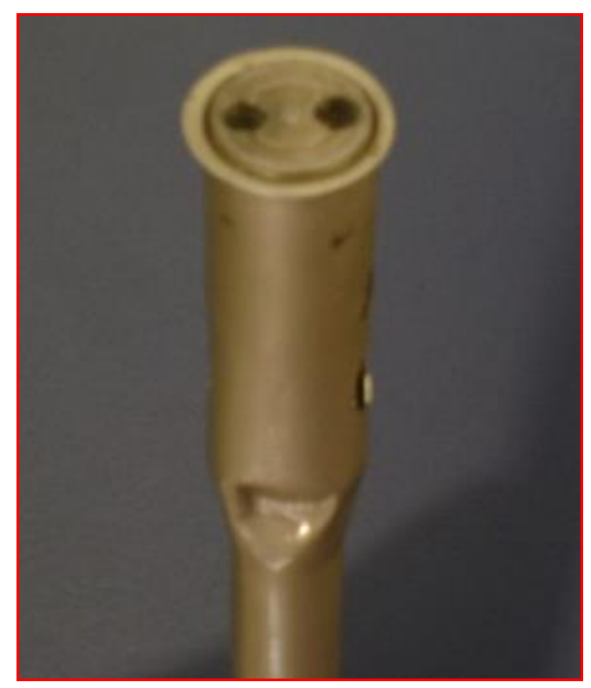

Fonte: Elaboração da pesquisa.

Após a câmera ter sua tampa posterior fixada na extremidade de maior diâmetro da cânula, ela teve seus fios embutidos também na cânula tendo sido a extremidade de menor diâmetro finalmente acoplada numa empunhadura de madeira, feita com o objetivo de tornar a sua manipulação mais ergonômica. A instalação da câmera foi realizada por mão de obra especializada.

Uma das pinças com grande função nos procedimentos laparoscópicos é a chamada pinça Hook, cujo a compra preço atinge cifras que impossibilitariam a sua aquisição sem comprometer o objetivo de produzir um produto com custos baixos.

Nesta linha de raciocínio, optamos por fabricá-la artesanalmente utilizando uma haste retirada de uma pinça vídeo laparoscópica descartável, através da qual foi introduzida uma vareta de aço cuja extremidade distal foi trabalhada de forma a atingir a forma de um gancho e na extremidade proximal foi soldado um fio, cuja a outra extremidade foi soldada a um plug tipo macho que se acopla num eletrocautério (figura 5). A conclusão da montagem do Manequim Vídeo Cirúrgico pode ser observada na figura 6. 
Figura 5 - Confecção da Pinça Hook

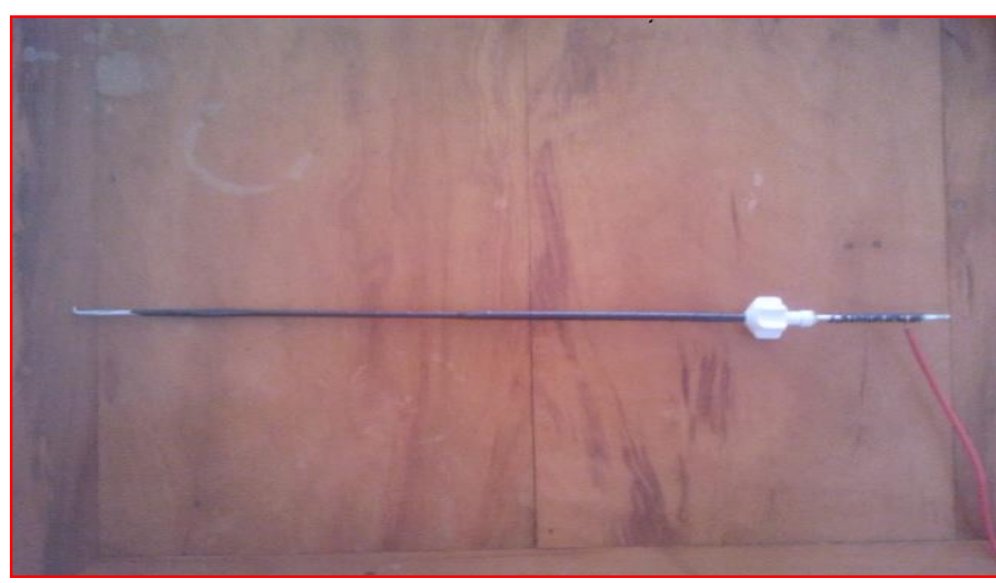

Fonte: Elaboração da pesquisa.

Figura 6 - Manequim cirúrgico de videolaparoscopia - visão externa.

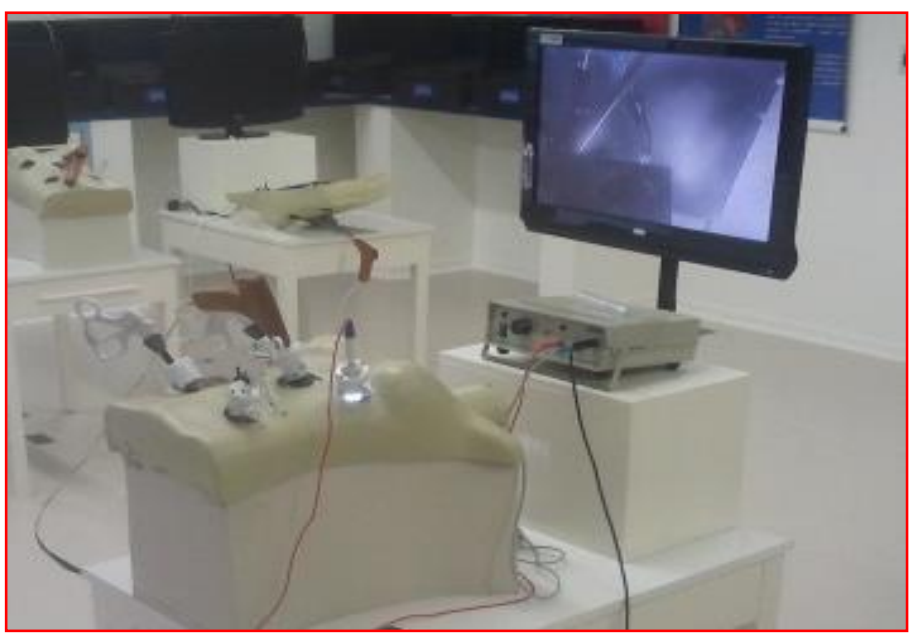

Fonte: Elaboração da pesquisa.

\section{Metodologia de aplicação do manequim}

Propõe-se utilizar o manequim com o intuito de promover a prática dos tempos básicos de uma cirurgia (diérese, hemostasia e síntese) aliada ao desenvolvimento das habilidades necessárias à execução de uma cirurgia vídeo laparoscópica num programa de Residência Médica em Cirurgia Geral. Este manequim difere dos outros existentes no mercado, uma vez que nele, a câmera não é fixa, o que permite a filmagem de vários ângulos, aproximações e distanciamentos, sendo necessário para a prática, a composição de uma dupla 
de trabalho, estimulando assim o entrosamento entre o operador da câmera e o executor do exercício (Figura 6), fator decisivo para a boa realização da cirurgia videolaparoscópica.

Figura 6 - Dupla na estação de trabalho
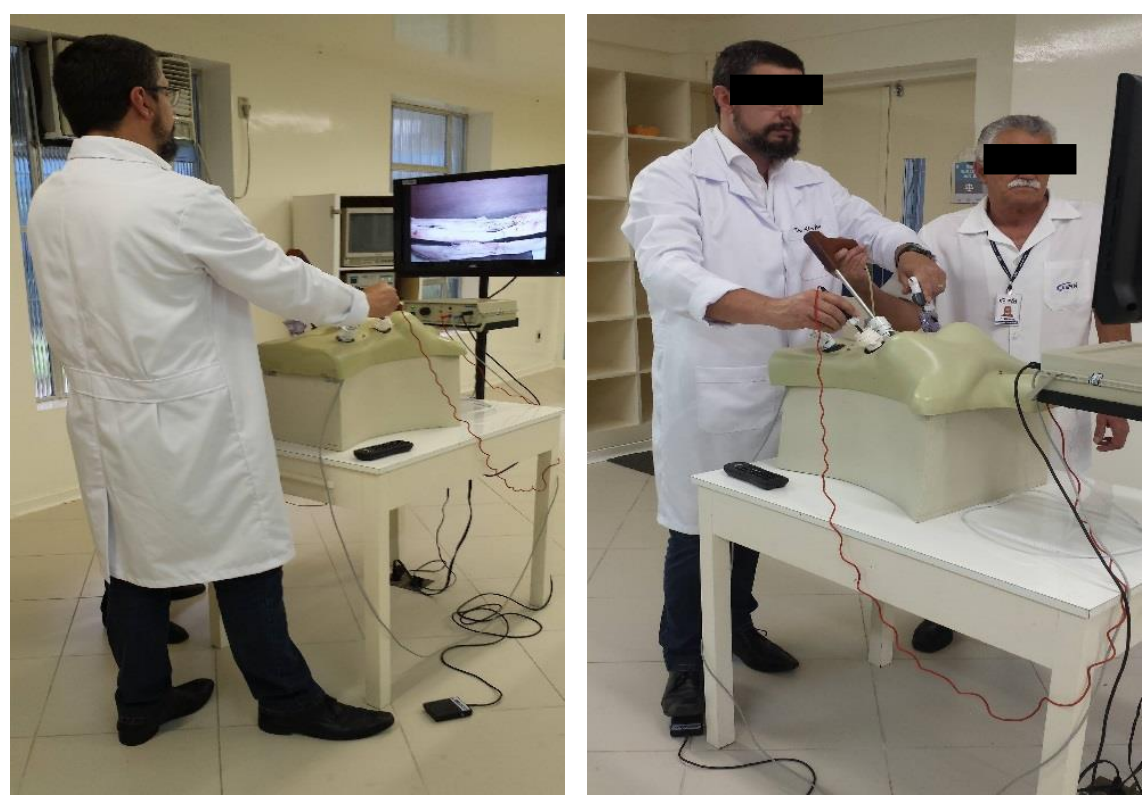

Fonte: Elaboração da Pesquisa.

Para a realização do exercício proposto, além do Manequim Cirúrgico, acoplado a uma televisão e a um eletrocautério, utiliza-se como material biológico, um pé de porco comprado em açougue e previamente preparado, através da retirada da pele e da fixação das extremidades através de parafusos à plataforma de trabalho em contato com a placa do eletrocautério, possibilitando assim a passagem de corrente elétrica alternada, simulando o tempo básico da hemostasia como ocorre durante a cirurgia.

Já no início do exercício ele permite simular as duas primeiras etapas básicas de um ato cirúrgico, ou seja, a diérese e a hemostasia, através da dissecção do tendão do pé de porco com a pinça Hook. No próximo passo, com o intuito de realizar outra atividade que proporcione o desenvolvimento de habilidades hemostáticas, é realizada a clipagem dupla do tendão, ele é então seccionado com tesoura laparoscópica entre os clips aplicados.

A etapa seguinte consiste na simulação do terceiro tempo cirúrgico, a síntese através da reconstituição do tendão dissecado e clipado, através da sutura das suas bordas. Para a 
realização da sutura, foi utilizado o ponto simples, com um fio de poliglactina 910, de diâmetro $n^{\circ} 0$, pelo fato de ser um fio com boa memória na confecção do nó, o que facilita sua realização feita pelo residente; com agulha cilíndrica, sendo o ponto ancorado nos clipes conforme ilustrado nas Figura 7.

Figura 7 - Sutura do tendão ancorada nos clips - passagem da agulha pela extremidade da direita
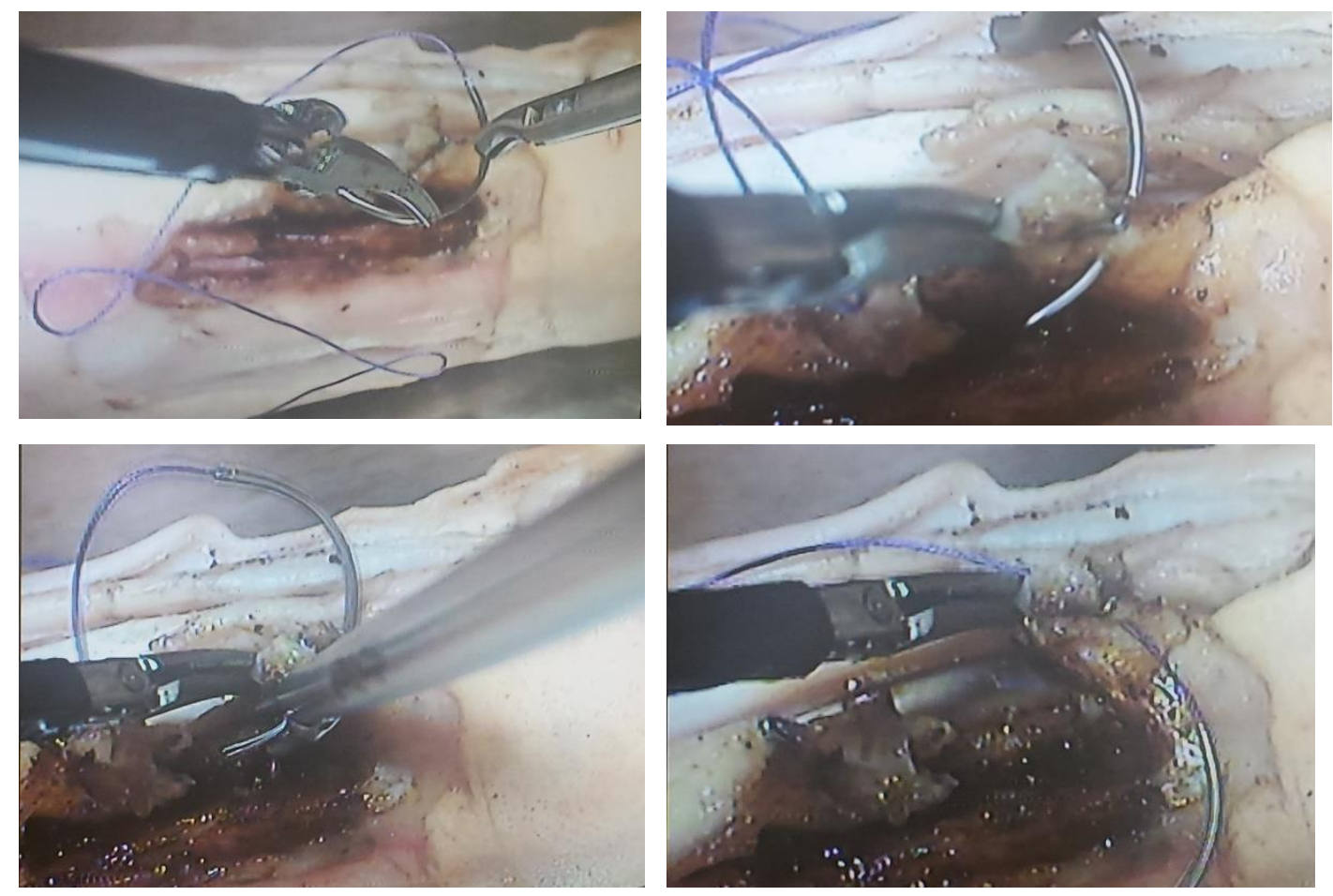

Fonte: Elaboração da pesquisa.

Após a montagem do manequim cirúrgico, foi proposto um exercício para os residentes com o material didático proposto e após a realização desse exercício, foi aplicado um questionário.

Os residentes de cirurgia geral do hospital municipal em que essa pesquisa foi realizada, foram convidados a realizarem no laboratório da Faculdade de Medicina de Volta Redonda, o exercício proposto. Por já estarem no segundo ano do programa de residência de cirurgia geral, estão acostumados a manipularem os instrumentais cirúrgicos da cirurgia vídeo laparoscópicas a cerca de um ano, pois no primeiro ano da residência eles já exercem a função da câmera durante estas cirurgias. Além disto, estes residentes já desenvolveram as 
habilidades cirúrgicas iniciais da cirurgia convencional durante o período da graduação, pois faz parte do currículo do curso de medicina a disciplina de Técnica Operatória e Cirurgia Experimental, em que os residentes aprendem a manipular os principais instrumentais cirúrgicos convencionais como porta agulha, a pinça de apreensão, a tesoura de cortar fios e também a realizar as principais suturas como o ponto simples e o ponto em X.

A análise da realização do exercício contou com uma técnica anglo-saxônica da década de 1940, que teve um aumento expressivo do seu emprego como pesquisa a partir da década de 1990 pela metodologia qualitativa. De acordo com Trad (2009), trata-se de uma técnica de pesquisa qualitativa de avaliação do usuário com um tipo de abordagem que enfatiza a necessidade de considerar a visão de diferentes sujeitos e contextos sobre os quais incidem o fenômeno a ser avaliado, aplicada através de um questionário, respondido após a realização do exercício e entrevista com o grupo de participantes selecionados, acima citado, baseandose na comunicação e na interação dos mesmos, tendo como principal objetivo, colher e reunir informações detalhadas sobre o Manequim Cirúrgico, bem como, proporcionar a compreensão de percepções sobre ele.

Objetivando a verificação da aplicabilidade do Manequim Cirúrgico, foram convidados os três residentes do segundo ano do programa de Residência de cirurgia geral do Hospital São João Batista em Volta Redonda, a realizarem o exercício proposto, no citado laboratório da Escola de Ciências Médicas de Volta Redonda, do Centro Universitário da Fundação Oswaldo Aranha, laboratório este, destinado pela faculdade, exclusivamente à pratica de habilidades vídeo cirúrgicas.

Por fim, criou-se um espaço para um questionário semiestruturado com os residentes do segundo ano aplicado por este pesquisador, considerando o processo de comunicação que ocorre entre pesquisador e participantes.

O questionário foi composto de sete questões com respostas objetivas que tinham finalidade de avaliar se os residentes tinham conhecimento do uso de manequins como ferramenta didática, e se este assunto já havia sido abordado durante o período já cursado de residência médica. De forma objetiva, buscou-se avaliar se os residentes haviam entendido e conseguido realizar as três etapas, além de opinarem se o Manequim Cirúrgico simulava a função da câmera e a função do cirurgião em relação aos tempos básicos da cirurgia. 
Partindo desses pressupostos e ideias centrais apresentadas neste material didático, a utilização do mesmo, certamente, fomentará o alcance dos objetivos traçados. Claro, que para atingir esses objetivos torna-se necessário um processo de aprendizado e treinamento prático duradouro e permanente na formação do residente, iniciando principalmente, no primeiro ano para que ocorra a transformação de todos os envolvidos nesse processo de ensinoaprendizagem.

\section{RESULTADOS E DISCUSSÃo}

Após a apresentação do Manequim Vídeocirúrgico como produto do Mestrado Profissional em Ensino em Ciências Médicas e do Meio Ambiente do UniFOA, houve a explicação de como se deu sua confecção a partir de materiais de baixo custo e de fácil obtenção e por fim a proposta de usá-lo como ferramenta didática do programa de residência de cirurgia geral.

Em seguida, após a explicação de como se deve realizar o exercício proposto, ele foi realizado pelos três residentes de cirurgia geral revezando-se nas funções de câmera e cirurgião, de modo que cada residente realizou por duas vezes a função de câmera e cirurgião assimilando os pontos de desenvolvimento das habilidades nas duas funções, bem como, a integração necessária à realização do exercício e, consequentemente, de uma cirurgia videolaparoscópica. Assim sendo, os residentes ao se alternarem nas duas funções puderam experimentar a possibilidade de desenvolverem não só as mesmas habilidades, mas também capacidade de interação, tão fundamental ao trabalho em equipe.

O próximo passo foi justificar a importância do manequim cirúrgico na formação destes residentes de cirurgia, pois nas residências médicas em cirurgia geral, os residentes já no primeiro ano do curso, manipulam aparelhos de videolaparoscopia na função de câmera, imergindo assim logo no início da residência no mundo da cirurgia vídeo laparoscópica.

Salientou-se a possibilidade que o Manequim Cirúrgico oferece ao residente de desenvolver suas habilidades minimizando a exposição do paciente a riscos desnecessários ao desenvolvimento da sua curva de aprendizagem. 
As respostas fornecidas pelos entrevistados sobre o conhecimento de algum simulador de cirurgia vídeo laparoscópica, pôde-se constatar que 02 dos residentes conhecia algum simulador, e apenas 01 afirmou que durante o período do programa de residência ao qual pertencem, já havia sido abordado de forma informal o assunto do uso de simulador de cirurgia vídeo laparoscópica como ferramenta didática de auxílio ao desenvolvimento de suas habilidades cirúrgicas.

Os residentes responderam de forma negativa quanto ao uso de manequins como forma complementar na formação de cirurgia geral, ou seja, não é uma realidade cotidiana no referido serviço de formação, e que a possibilidade de seu uso como ferramenta didática em sua formação não é usualmente discutida neste programa de residência médica em cirurgia geral, o que aponta a originalidade desse estudo.

Quanto ao entendimento das etapas realizadas no exercício proposto, terceira pergunta do questionário, todos responderam afirmativamente terem entendido as três etapas, demonstrando que o exercício é de fácil compreensão, passível de ser realizado por residentes, e complementa o aprendizado na fase inicial de sua especialização.

As respostas dos residentes na questão 4 do questionário "Você conseguiu realizar as três etapas do exercício proposto?" foi possível perceber todos entrevistados conseguiram realizar as etapas do exercício proposto. Os residentes foram unânimes para as perguntas 5 "Você acha que o manequim simula a função do câmera?"; 6 "Você acha que o manequim simula a função do cirurgião em relação aos tempos básicos da cirurgia?"; e, 7 "Você acredita que a presença de um simulador num programa de residência pode estimular o processo ensino-aprendizagem da residência médica em cirurgia geral?" do questionário, quando afirmaram que o manequim simula as funções do câmera e do cirurgião em relação aos tempos básicos da cirurgia e, em sua totalidade, os residentes acreditam que a presença de um simulador num programa de residência médica em cirurgia geral pode estimular o processo ensino-aprendizagem.

Por fim em relação à questão aberta, pergunta 8 do questionário, "Observações que julgar pertinentes", seguem os transcritos:

"O manequim foi bem desenvolvido. Considero uma boa ferramenta de aprendizado e treinamento prático"

"O simulador foi de grande valia, acho importante para o residente, principalmente do primeiro ano" 
"O simulador permite a prática da habilidade mais difícil, na minha opinião, da vídeolaparoscopia, que éo nó"

Esses transcritos da pergunta subjetiva mostram que no espaço oferecido às observações pertinentes, os residentes opinaram dizendo que o Manequim Cirúrgico é uma boa ferramenta desenvolvida para seu aprendizado prático, principalmente por permitir a prática mais difícil, ou seja, o nó cirúrgico vídeo laparoscópico.

\section{CONSIDERAÇÕES FINAIS}

A partir das considerações apresentadas, foi possível observar que uma das contribuições significativas para a formação universitária na área médica, especialmente na área cirúrgica, é o fato da construção do conhecimento científico estar definitivamente associada à evolução tecnológica. Os obstáculos que concernem os conhecimentos dos residentes na questão da prática da vídeocirurgia estão inseridos também, na falta de oportunidade deles realizarem procedimentos durante sua formação. E, formar profissionais competentes requer metodologias aplicáveis, interessantes e seguras, não apenas para o ensino científico, mas também para a aquisição prévia de prática, como no caso de uma cirurgia videolaparoscópica.

O recurso metodológico e didático apresentado nesse trabalho, o Manequim Cirúrgico de Videolaparoscopia, demonstrou contribuir para o estímulo do aprendizado consciente da cirurgia vídeolaparoscópica, considerada uma realidade nos dias de hoje. Desse modo, verificou-se a necessidade de se introduzir cada vez mais, novas tecnologias no aprendizado do futuro cirurgião para que ele se adapte a esta nova modalidade cirúrgica e, o Manequim Cirúrgico de Videolaparoscopia, é uma proposta que promove constante busca pelo alcance no aprimoramento do conhecimento do médico residente.

Espera-se que recurso didático possa contribuir para a fixação dos conhecimentos adquiridos pelos residentes durante a residência médica de cirurgia geral e estimulá-los a se interessarem ainda mais pela especialização cirúrgica para que venham de forma consciente, desenvolver suas atividades como futuros profissionais, minimizando riscos de acidentes e 
doenças ocupacionais decorrentes dessas atividades. 0 momento agora é adaptar as diretrizes à realidade de cada um dos cursos de Medicina com intuito de ajustá-las para realmente formar profissionais aptos nas diversas áreas médicas.

\section{REFERÊNCIAS}

BRANDÃO, C. R.; BORGES, M. C. (2007)- A Pesquisa Participante.Rev. Ed. Popular, Uberlândia, v. 6, p.51-62. jan./dez.

BRASIL. Lei 9.605/98: Sanções penais e administrativas derivadas de condutas e atividades lesivas ao meio ambiente. Capítulo V. Dos crimes contra o meio ambiente. Seção I: Dos Crimes contra a Fauna. Brasília, 1998.

FLEXNER, A. Análise do ensino médico pela Fundação Carnegie faz um século: Introdução ao relatório Flexner 1910. Revista Ensino Superior Unicamp. Marco 2010.

MONDARDO, A.H. e PEDON, E.A. Estresse e desempenho acadêmico em estudantes universitários. Revista de Ciências Humanas. v.17, n.29, 2011. Disponível em: http://revistas.fw.uri.br/index.php/revistadech/index.

NETO, J.A.C.; SIRIMARCO, M.T.; FIGUEIREDO, N.S.V.; BARBOSA, T.N.; SILVEIRA, T.G. Erro Médico: a Perspectiva de Estudantes de Medicina e Direito. Revista brasileira de educação médica. v.35, n.1, p.5-12, 2011.

RODRIGUES, D.F. Novas perspectivas para o ensino de cirurgia em medicina veterinária. [Dissertação]. Goiânia: UFG, 2012. Disponível em: http://ppgca.evz.ufg.br/up/67/o/1\%C2\%BA_SEMIN\%C3\%81RIODANILO_FERREIRA_RODRIGUES.pdf?1352294720. Acesso em jul/2017.

SANTA-ROSA, J.G. e STRUCHINER, M. Tecnologia Educacional no Contexto do Ensino de Histologia: Pesquisa e Desenvolvimento de um Ambiente Virtual de Ensino e Aprendizagem. Revista Brasileira de Educação Médica. $\begin{array}{llll}\text { v.35, } & \text { n.2, } & \text { p.289-298, } & 2011 .\end{array}$ Disponível:https://repositorio.ufrn.br/jspui/bitstream/123456789/18552/1/Jos\%c3\%a9\%20Guilherme\%20da\% 20Silva\%20Santa\%20Rosa_Tecnologia\%20educacional\%20no\%20contexto.pdf. Acesso em jul/2017.

TRAD, L.A. B. Grupos focais: conceitos, procedimentos e reflexões baseadas em experiências com o uso da técnica em pesquisas de saúde. Physis Revista de Saúde Coletiva. Rio de Janeiro, v.19, n.3, p.777-796, 2009. Disponível em: http://www.scielo.br/pdf/physis/v19n3/a13v19n3.pdf. Acesso em fev/2017

VALENTE, J.A. A espiral da aprendizagem e as tecnologias da informação e comunicação (TIC): repensando conceitos. [Dissertação]. (2012). Disponível em: http://www.bibliotecadigital.unicamp.br/DissertaçõesTeses/pdf. Acesso em jul/2017

ZANETTI, M.B.F. O uso experimental de animais como instrumento didático nas práticas de ensino no curso de medicina veterinária. IX Congresso Nacional de Educação - EDUCERE. III Encontro Sul Brasileiro de Psicopedagogia, 26 a 29 de outubro de 2009 - PUCPR. Disponível em: http://www.pucpr.br/eventos/educere/educere2009/anais/pdf/3558_2032.pdf. Acesso em julho/2017.

\section{(cc) Br}

Este trabalho está licenciado com uma Licença Creative Commons - Atribuição 4.0 Internacional. 